Archives de sciences sociales des religions

112 | octobre-décembre 2000

Âme et corps : conceptions de la personne

\title{
ZETLAOUI (Monique), Shalom India. Histoire des communautés juives en Inde
}

Paris, Imago, 2000, 378 p. (bibliogr.)

\section{Régine Azria}

\section{OpenEdition}

\section{Journals}

Édition électronique

URL : http://journals.openedition.org/assr/20497

DOI : $10.4000 /$ assr. 20497

ISSN : 1777-5825

Éditeur

Éditions de l'EHESS

Édition imprimée

Date de publication : 31 décembre 2000

Pagination : 176-177

ISBN : 2-222-96698-1

ISSN : 0335-5985

\section{Référence électronique}

Régine Azria, «ZETLAOUI (Monique), Shalom India. Histoire des communautés juives en Inde », Archives de sciences sociales des religions [En ligne], 112 | octobre-décembre 2000, document 112.115, mis en ligne le 19 août 2009, consulté le 21 septembre 2020. URL : http://journals.openedition.org/assr/ 20497 ; DOI : https://doi.org/10.4000/assr.20497

Ce document a été généré automatiquement le 21 septembre 2020

(C) Archives de sciences sociales des religions 


\section{ZETLAOUI (Monique), Shalom India. Histoire des communautés juives en Inde}

Paris, Imago, 2000, 378 p. (bibliogr.)

Régine Azria

\section{RÉFÉRENCE}

ZETLAOUI (Monique), Shalom India. Histoire des communautés juives en Inde, Paris, Imago, 2000, 378 p. (bibliogr.)

1 Les juifs du sous-continent indien se répartissent entre trois groupes: les juifs de Cochin, les Bene Israel et les Baghdadi. La présence des deux premiers en Inde est très ancienne et fait l'objet de nombreuses légendes et hypothèses. Quant aux troisièmes, originaires d'Irak, ils ne s'y établissent que tardivement, au XIX ${ }^{\mathrm{e}}$ siècle et y prospèrent dans le commerce. Récemment, un quatrième groupe de quelques milliers de personnes, les Mizos, vivant aux confins de la Birmanie, se revendique juif, descendant de la tribu de Manassé.

2 Les Bene Israel, les plus nombreux, installés à Bombay et Calcutta et les juifs de Cochin (actuel Kérala) se partagent entre «blancs » - paradesi ou gora - et " noirs » - malabari ou kala. Cette distinction liée à la couleur de la peau vise à présenter les «blancs » comme une race pure, assimilable aux brahmanes, et les «noirs» comme des descendants d'esclaves africains convertis et par conséquent «intouchables ». Il va de soi que les deux groupes ne se marient pas entre eux. À la différence des Bagdadi, qui sont demeurés étrangers à la culture et à la société indienne, les juifs de Cochin et les Bene Israel se sont intégrés à cette société et ont adopté certaines de ses pratiques, notamment le système des castes. Spécialisés dans le commerce des épices (surtout le poivre), du bois, de l'opium, des textiles, les juifs blancs ont connu une certaine prospérité et n'ont pas eu à souffrir de l'antisémitisme, sauf durant la période 
portugaise. La plupart des juifs indiens ont émigré et ceux qui sont allés en Israël rencontrent les plus grandes difficultés pour se faire reconnaître comme juifs par les autorités religieuses.

3 L'ouvrage retrace l'histoire de ces communautés et dresse le portrait des personnalités les plus marquantes. Trop d'anecdotes, de détails, de digressions inutiles en rendent la lecture parfois pénible. Mais on saura gré à l'auteur de porter à la connaissance du public francophone une diaspora méconnue, sinon mal connue. 